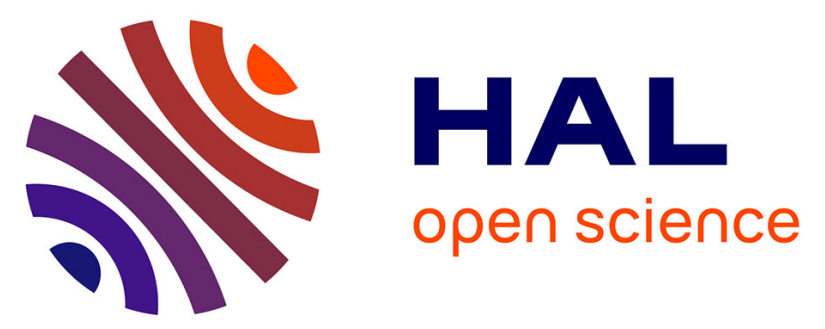

\title{
Performance and dynamic modeling of a continuously operated pomace olive packed bed for olive mill wastewater treatment and phenol recovery
}

Amina Lissaneddine, Laila Mandi, Mounir El Achaby, Emmanuel Mousset, Eldon R. Rene, Naaila Ouazzani, Marie-Noëlle Pons, Faissal Aziz

\section{To cite this version:}

Amina Lissaneddine, Laila Mandi, Mounir El Achaby, Emmanuel Mousset, Eldon R. Rene, et al.. Performance and dynamic modeling of a continuously operated pomace olive packed bed for olive mill wastewater treatment and phenol recovery. Chemosphere, 2021, 280, pp.130797. 10.1016/j.chemosphere.2021.130797 . hal-03430315

\section{HAL Id: hal-03430315 https://hal.science/hal-03430315}

Submitted on 16 Nov 2021

HAL is a multi-disciplinary open access archive for the deposit and dissemination of scientific research documents, whether they are published or not. The documents may come from teaching and research institutions in France or abroad, or from public or private research centers.
L'archive ouverte pluridisciplinaire HAL, est destinée au dépôt et à la diffusion de documents scientifiques de niveau recherche, publiés ou non, émanant des établissements d'enseignement et de recherche français ou étrangers, des laboratoires publics ou privés.

\section{(1) (1) $\$$}

Distributed under a Creative Commons Attribution - NonCommercial - NoDerivatives 44.0 


\section{Performance and dynamic modeling of a continuously operated}

\section{pomace olive packed bed for olive mill wastewater treatment and}

\section{phenol recovery}

Amina Lissaneddine ${ }^{\mathrm{a}, \mathrm{b}, \mathrm{c}}$, Laila Mandi ${ }^{\mathrm{a}, \mathrm{b}}$, Mounir El Achaby ${ }^{\mathrm{d}}$, Emmanuel Mousset $^{\mathrm{c}}$, Eldon R.

Rene $^{\mathrm{e}}$, Naaila Ouazzani ${ }^{\mathrm{a}, \mathrm{b}}$, Marie-Noëlle Pons ${ }^{\mathrm{c}}$, Faissal Aziz ${ }^{\mathrm{a}, \mathrm{b},{ }^{*}}$

${ }^{a}$ Laboratory of Water, Biodiversity, and Climate Change, Faculty of Sciences Semlalia, Cadi Ayyad University, B.P. 2390, 40000, Marrakech, Morocco

${ }^{b}$ National Center for Research and Studies on Water and Energy (CNEREE), Cadi Ayyad University, B. 511, 40000, Marrakech, Morocco

${ }^{\mathrm{c}}$ Laboratoire Réactions et Génie des Procédés (LRGP), CNRS/Université de Lorraine (UMR 7274), Nancy, France

${ }^{\mathrm{d}}$ Materials Science and Nano-engineering (MSN) Department, Mohammed VI Polytechnic University (UM6P), Benguerir, Morocco

${ }^{\mathrm{e}}$ Department of Water Supply, Sanitation and Environmental Engineering, IHE Delft Institute for Water Education, PO. Box 3015, 2601 DA, Delft, the Netherlands

\section{ACCEPTED IN}

\section{CHEMOSPHERE JOURNAL}




\section{Abstract}

The solid waste of olive oil extraction processes (olive pomace (OP)) was converted into activated carbon (AC) through merely treating it with $\mathrm{NaOH}$ and then encapsulating it within sodium alginate (SA) in beads by crosslinking (SA-AC beads). The prepared SA-AC beads were utilized as an adsorbent for the elimination and recovery of phenolic compounds (PCs) from olive mill wastewater (OMWW) following a zero liquid and waste discharge approach to implement and promote the circular economy concept. The novel AC and SA-AC beads were characterized by scanning electron microscopy (SEM), energy-dispersive X-ray spectroscopy (EDS), Fourier transform infrared spectroscopy (FTIR) and Brunauer, Emmett and Teller (BET) analysis. The adsorption performance of these beads was evaluated in batch and fixedbed reactors operated in a concurrent flow system. The results revealed that an adsorption capacity of $68 \mathrm{mg} \mathrm{g}^{-1}$ was attained for $4,000 \mathrm{mg} \mathrm{L}^{-1}$ phenolic compounds. The kinetics of the adsorption process of the PCs fit a pseudo second-order model, and the most likely mechanism took place in two stages. The adsorption isotherm conformed to the Langmuir model, representing the monolayer adsorption of the phenolic compounds. The dynamic models were used, and they accurately represented the breakthrough curves. Considering PC recovery and process reusability, a regeneration experiment of SA-AC beads was carried out in fixed-bed reactors. SA-AC beads showed a high percentage desorption $>40 \%$ using ethanol and were efficient after several cycles of OMWW treatment and phenol recovery.

Keywords: Olive pomace; Olive mill wastewater; Phenolic compounds; Activated carbonbeads; Adsorption; Regeneration. 


\section{Introduction}

Oil mills generating olive oil in the Mediterranean region have a significant economic position, representing 98\% of global olive oil production (Bampalioutas et al., 2019; Al-Bsoul, et al., 2020). Olive oil extraction is achieved via modern or traditional processes. Generally, two waste fractions are produced regardless of the extraction technique (Kaleh, 2016) in seasonal time intervals (Annab et al., 2019): solid waste (OP) and liquid effluent (OMWW). Unfortunately, OMWW has a high polluting power due to a high chemical and biochemical oxygen demand after 5 days (COD and $\mathrm{BOD}_{5}$ ) (Ji et al., 2019). Furthermore, they are saturated by phenolic and aromatic compounds that are toxic and extremely difficult to biodegrade (Baierle et al., 2019). Environmental legislation in Morocco requires that the discharge from olive mills have a $\mathrm{pH}$ ranging between 6 and 9, a concentration of PCs of $0.5 \mathrm{mg} \mathrm{L}^{-1}$, an electrical conductivity that

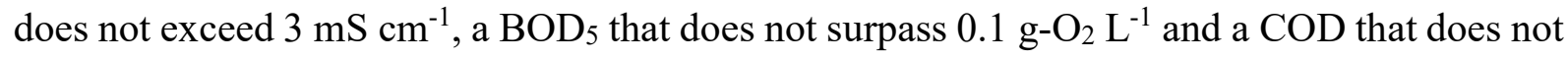
go over 0.5 g-O $\mathrm{L}^{-1}$ (Pinto et al., 2005; El Moudden et al., 2019).

Tyrosol, hydroxytyrosol, vanillic acid, gallic acid, p-hydroxyphenyl acetic acid, caffeic acid and p-coumaric acid are considered the dominant PCs in OMWW (Bressan et al., 2004). The toxicity of OMWW is largely attributed to these phenolic compounds. In addition to their high cost, traditional physicochemical and biological systems applied for OMWW treatment have limited effectiveness. Thus, possible treatment techniques are necessary to reach a suitable solution for the elimination of these compounds (Kilic et al., 2019, El Ghadraoui et al., 2020; Elmansour et al. 2020). However, many technologies have recently been investigated for recovery of PCs from OMWW, such as physical, thermal, physicochemical and biological technologies (Rahmanian et al., 2013). Azzam and Hazaimeh (2021) used liquid-liquid extraction to recover PCs from OMWW using ethyl acetate as a solvent; Zagklis et al. (2015) used resin adsorption/desorption for the recovery of hydroxytyrosol from OMWW, and Achak 
et al. (2009) used adsorption followed by desorption for the recovery of total PCs from OMWW using banana peel as a biosorbent.

Adsorption is the most widely used and effective technique for removing environmental pollutants (Sun et al., 2019). In recent years, many adsorbents, such as activated carbons (ACs), have been used to eliminate PCs (Annab et al., 2019). AC is commonly used because of its microporous texture, high surface reactivity, consistency in the distribution of pore size, wide spectrum of functional surface groups and thermal steadiness (Shim et al., 2019).

A column reactor is a practical and simple device that reduces the costs of and energy needed for water treatment by exploiting the concentration gradient between the adsorbent and pollutants, producing high-quality treated effluents with a minimum pollutant concentration on an ongoing basis (Basu et al., 2019). However, due to the small particle size of AC, its application in continuous flow adsorption systems has some disadvantages, such as bed compaction and a high-pressure drop in fixed bed column systems (Aziz, et al., 2020). To avoid such drawbacks, the encapsulation of AC in alginate hydrogels is an attractive alternative with high applicability for continuous flow adsorption processes (Aziz, et al., 2020; Quesada et al., 2020). Alginate gels are highly permeable due to their porous texture and hydrophilicity, providing important advantages due to their high affinity and adsorption potential for several micropollutants, such as heavy metal ions and dyes (Arenales-Sierra et al., 2019; Quesada et al., 2020). The wastewater treatment operation at the real scale requires granular materials of controlled size, which numerous researchers had to generate those materials by the encapsulation of diverse adsorbents in the alginate composite to improve their potentials (Aziz et al., 2020).

Currently, many researchers use beads with alginate coatings on several kinds of sorbent materials or functionalize them to be more efficient and teste the obtained composites for OMWW PCs or synthetic effluent (Jodra and Mijangos 2007; Kim et al., 2008; Siva Kumar et 
al., 2009; Duarte et al., 2014). Duarte et al. (2014) used silica-alginate-fungi biocomposites; Siva Kumar et al. (2009) investigated chitosan-calcium (CS/Ca) alginate blended beads; Kim et al. (2008) used an alginate-activated carbon (AAC) bead and Jodra and Mijangos (2007) used a calcium alginate-AC composite bead. Although numerous studies exist on the application of alginate composite beads for the treatment of PCs of OMWW or synthetic phenol from water exist, this is the first work on the combined use of olive mill wastes and alginate for the adsorption and recovery of PCs from real OMWW.

In a similar work, Annab et al. (2019) investigated beads based on AC encapsulated in calcium alginate to adsorb polyphenols from OMWW. This work succeeded in attaining a high level of adsorption capacity of their synthesized material for polyphenols. In addition, the activation of the pomace used in this work was accomplished with KOH. Furthermore, these beads were tested under batch and column conditions on only synthetic effluent and OMWW diluted in ultrapure water, i.e., without the high concentrations that are characteristic of real effluents. All these reasons make their results not easily applicable to industrial applications. Therefore, it is suggested in the present work to use raw effluent and $\mathrm{AC}$ treated with $\mathrm{NaOH}$ before transforming it into beads for the first time and to characterize the PCs adsorbed from OMWW by liquid chromatography.

The objective of this study is to carry out a cycle of olive mill waste treatment in which OP is first converted into a highly porous AC to be used for the treatment of OMWW by adsorption. The kinetics, mechanism and adsorption isotherms of PC adsorption were investigated. The experiments were carried out under different operational conditions (time, concentration, $\mathrm{pH}$, temperature) to determine the adsorbent behavior in stirred batch and fixed-bed reactors. PC recovery and the process reusability of SA-AC beads were carried out in fixed-bed reactors.

\section{Materials and methods}

\subsection{Sample collection and characterization}


OMWW was sampled from modern and traditional oil mills located in the region of Marrakech in Morocco during the olive oil extraction season from December to March during the 2019/2020 campaign. The collected samples were subjected to various physicochemical analyses according to the methods of analysis as indicated in Table S1 (in the Supplementary material). The $\mathrm{pH}$, temperature, TDS (total dissolved solids), salinity and EC (electrical conductivity) were measured by a Hanna HI 9829 probe (Kallang Road, Singapore). The COD, suspended matter and volatile matter in suspension, ammonium and total phosphorus and orthophosphates were analyzed according to AFNOR standards. The PCs were measured using the Folin-Ciocalteu method (Singleton and Rossi, 1965) using caffeic acid as a standard.

\subsection{Preparation of activated carbon}

OP was collected from modern oil mills located in the region of Marrakech in Morocco. It was dried at $105^{\circ} \mathrm{C}$ overnight and then ground to a coarse aggregate. The activation process was performed using chemical activation. Ten grams of precursor (olive pomace) was physically mixed with 5 M sodium hydroxide (98-100.5\% purity, Sigma-Aldrich) at a weight ratio (activator/precursor) of 1:1 by stirring for $1 \mathrm{~h}$. The material was thoroughly washed and filtered using deionized ultrapure water until a $\mathrm{pH}$ of 7 was obtained. Finally, the material was placed in a furnace at room temperature. The adsorbent was heated to $700^{\circ} \mathrm{C}$ with a temperature increase rate of $10^{\circ} \mathrm{C}$ per minute. The material was then kept in the furnace (SF7/S Stuart, United Kingdom) at $700^{\circ} \mathrm{C}$ for $30 \mathrm{~min}$.

\subsection{Preparation of beads}

Composite beads (sodium alginate (SA) - AC) were prepared via the crosslinking process. The process for preparing the composite beads consists of first producing a primary mixture of the hydrogel of sodium alginate (BioChemica) $(1 \%)$ at $25^{\circ} \mathrm{C}$. The AC powder $(1 \%)$ was then added to the alginate hydrogel under constant stirring to prepare a homogeneous dispersion $(24 \mathrm{~h})$. The second step was to pour the secondary mixture dropwise into a crosslinking solution of 
iron $20 \mathrm{~g} \mathrm{~L}^{-1}$ (iron(III) chloride hexahydrate, 99\%, ACROS Organics). Bead solidification was performed for $24 \mathrm{~h}$. Finally, the aggregated SA-AC beads were thoroughly washed with ultrapure water and stored in ultrapure water.

\subsection{Characterization}

FTIR was used to assess the functional groups on the surface of the AC and beads. The FTIR spectra were obtained by ALPHA FT-IR Spectrometer (ALPHA-P, Germany) in the wavelength range of 400 to $4000 \mathrm{~cm}^{-1}$. Each spectrogram consisted of an average of 60 scans. Morphological examination of the SA-AC beads was performed by using SEM measurements, which were taken with a TESCANTM VEGA3 scanning electron microscope (Fuveau, France). An EDS analyzer (TEAM ${ }^{\mathrm{TM}}$ EDS) enabled the analysis of elements on the micro-scale and element distribution on the SA-AC beads. The BET method was used to calculate the specific surface area $\left(\mathrm{S}_{\mathrm{BET}}\right)$ and the total volume $\left(V_{T}\right)$ of $\mathrm{AC}$ and $\mathrm{SA}-\mathrm{AC}$ beads that had been previously outgassed and assessed by nitrogen adsorption at $-196^{\circ} \mathrm{C}$ (via a Micromeritics ASAP 2020 surface analyzer system).

The average pore radius $\left(r^{-}\right)$was calculated from Eq. 1 (Lawal et al., 2020):

$r^{-}(n m)=\frac{2 V_{T}}{S_{B E T}} \times 10^{3}$

\subsection{Experimental setup and procedure}

\subsubsection{Stirred batch sorption experiments}

Batch tests were achieved by adding $5 \mathrm{~g}$ of SA-AC beads to a $5 \mathrm{~mL}$ OMWW sample for the optimal time in tubes in a rotary mixer under continuous stirring (KS 3000 i control, Germany) at $200 \mathrm{rpm}$. Isotherm studies were performed on the prepared SA-AC with OMWW of various concentrations $(20,40,80,100,250,800,1,000,1,500,2,000,2,500,3,000,3,500$ and 4,000 $\mathrm{mg} \mathrm{L}^{-1}$ ) for $24 \mathrm{~h}$ and at $\mathrm{pH} \mathrm{4,} \mathrm{which} \mathrm{corresponds} \mathrm{to} \mathrm{the} \mathrm{pH}$ of the real effluent. In a subset of experiments, the $\mathrm{pH}$ of the OMWW solution was adjusted from 4 to 10 using $1.0 \mathrm{M} \mathrm{NaOH}$ or $\mathrm{HCl}$. The control tests samples were agitated without SA-AC beads under the same conditions. 
All experiments were performed at ambient temperature $\left(19^{\circ} \mathrm{C}\right)$ and were performed in duplicate.

\subsubsection{Column sorption experiments}

The continuous system assays were performed with a column with a $4 \mathrm{~cm}$ interior diameter and a height of $30 \mathrm{~cm}$. The $\mathrm{SA}-\mathrm{AC}$ beads $(140 \mathrm{~g})$ were introduced into the column. The OMWW was introduced in ascending flow using a peristaltic pump (Antlia - 3C Dutscher, France) at a constant flow rate of $2 \mathrm{~mL} \mathrm{~min}^{-1}$. At the outlet of the column, the OMWW was sampled at regular time intervals, and the PC concentration was measured. All tests were carried out in duplicate.

To assess the reusability of this newly generated material, PC desorption from SA-AC beads in the liquid phase was examined in fixed-bed reactors. After the adsorption experiment, the SA-AC beads were rinsed with distilled water three times to eliminate PCs on the surface, targeting the adsorbed fraction. The desorption tests were then performed with ethanol due to the selectivity of this solvent for PCs (Zagklis et al., 2018). Desorption was performed with 5 $\mathrm{mL}$ ethanol per $\mathrm{g}$ of SA-AC beads. At a constant temperature, ethanol was pumped into the column at a fixed flow rate of $2 \mathrm{~mL} \mathrm{~min}^{-1}$ for $3 \mathrm{~h}$. The PCs concentrations were determined at various time intervals from the beginning of the desorption operation.

\subsection{Analytical method}

The phenolic extracts were analyzed by high-performance liquid chromatography (HPLC). AKnauer-HPLC chromatograph equipped with a diode array detector and accompanied by software for processing the data was used. The column had a reversed-phase polarity (Eurospher II 100-5 C-18, 250x4.6). The mobile phase was a gradient of acetonitrile and bidistilled water acidified to $\mathrm{pH} 2.6$ with O-phosphoric acid. The separation lasted $1 \mathrm{~h}$ according to a linear gradient program of acetonitrile/water and was performed at a temperature of $25^{\circ} \mathrm{C}$, a pressure of 400 bar and a flow rate of $1 \mathrm{~mL} \mathrm{~min}^{-1}$. 


\subsection{Batch and fixed-bed column data analysis}

To understand and explain the adsorption process of PCs onto beads, Langmuir and Freundlich adsorption isotherm models were presented in this study; according to many references (Badawi et al. 2017; Olusegun, et al. 2018; Es-sahbany et al. 2019), these two models are considered compatible models to describe the sorption phenomena.

The Langmuir isotherm equation (Eq. 2) shows an adsorption model of a homogeneous system with a single layer and is expressed as (Langmuir, 1916):

$\frac{C_{e}}{q_{e}}=\frac{1}{K_{L} \times q_{m}}+\frac{C_{e}}{q_{m}}$

where $q_{e}\left(\mathrm{mg} \mathrm{g}^{-1}\right)$ is the PCs amount adsorbed at equilibrium; $C_{e}\left(\mathrm{~g} \mathrm{~L}^{-1}\right)$ is the equilibrium concentration of PCs in solution; $K_{L}$ is the Langmuir constant related to the energy of adsorption $\left(\mathrm{L} \mathrm{g}^{-1}\right)$; and $q_{m}\left(\mathrm{mg} \mathrm{g}^{-1}\right)$ is the maximum PCs adsorption capacity.

The Freundlich adsorption isotherm model is applied for multiple layer adsorption founded on a heterogeneous process. The Freundlich adsorption isotherm equation (Eq. 3) is (Freundlich, 1906):

$\ln q_{e}=\ln K_{f}+\frac{1}{n} \times \ln C_{e}$

where $K_{f}$ is a Freundlich constant that presents the adsorption capacity of the adsorbent and n is a constant that presents the greatness of the relationship between PCs and SA-AC beads.

To further explain the elimination process of PCs onto SA-AC beads, two kinetic models were investigated. The adsorption kinetics data have been compared with the pseudo-first order and pseudo-second order rate equations; according to many references, these two models are used to define the sorption mechanisms (Lagergren, 1898; Ho, 1999):

$$
\begin{aligned}
& \log \left(q_{e}-q_{e}\right)=\log \left(q_{e}\right)-\frac{K_{1}}{2.303} \times t \\
& \frac{t}{q_{t}}=\frac{1}{K_{2} \times q_{e}^{2}}+\frac{t}{q_{e}}
\end{aligned}
$$


Where $q_{e}$ and $q_{t}$ are the amounts of PCs adsorption onto SA-AC beads at equilibrium and time $t$, respectively, and $k_{1}$ and $k_{2}$ are the pseudo-first order and pseudo-second order rate constants, respectively.

A temperature study on the adsorption of PCs on alginate beads at various temperatures (19$\left.35^{\circ} \mathrm{C}\right)$ was performed. The thermodynamic parameters, i.e., the Gibbs energy $\left(\Delta G\right.$ in $\left.\mathrm{kJ} \mathrm{mol}^{-1}\right)$, standard entropy $\left(\Delta S\right.$ in $\left.\mathrm{J} \mathrm{mol}^{-1} \mathrm{~K}^{-1}\right)$ change, and standard enthalpy $\left(\Delta H\right.$ in $\left.\mathrm{kJ} \mathrm{mol}^{-1}\right)$ change, of the adsorption process were calculated from the following equations (Eqs. 6-9) (Li, et al. 2019):

$\Delta G=-R \times T \times \ln K_{c}$

$\Delta G=\Delta H-T \times \Delta S$

$\ln K_{c}=-\frac{\Delta H}{R \times T}+\frac{\Delta S}{R}$

where $K_{c}$ is the thermodynamic distribution coefficient calculated by Eq. 9:

$K_{c}=\frac{q_{e}}{C_{e}}$

where $q_{e}$ and $\mathrm{C}_{\mathrm{e}}$ are equilibrium concentrations $\left(\mathrm{g} \mathrm{L}^{-1}\right)$ of adsorbate on the adsorbent and the solution, respectively.

The values of the important design parameters of the breakthrough curves of the column for PCs adsorption onto the SA-AC beads were calculated. The volume of the effluent, $V_{\text {ef }}(\mathrm{mL})$, was calculated with the following equation:

$V_{e f}=Q \times t_{\text {total }}$

Where $t_{\text {total }}$ is the total time (min) and $Q$ is the flow rate that circulates through the column (mL $\left.\min ^{-1}\right)$

The pic area of the breakthrough curve signifies the total mass of PCs biosorbed, $q_{\text {total }}(\mathrm{mg})$, for a specific feed concentration and flow rate and can be calculated by integration as follows:

$q_{\text {total }}=\frac{Q}{1000} \times \int_{0}^{t_{\text {total }}} C_{R} \times d t$

where $C_{R}$ is the concentration of PCs removal $\left(\mathrm{mg} \mathrm{L}^{-1}\right)$.

The total amount of PCs sent to the column (mg) can be determined from the equation below: 
$m_{\text {tot }}=\frac{C_{i} \times Q \times t_{\text {total }}}{1000}$

and the total metal removal (\%) can be determined from the ratio of PCs mass adsorbed $\left(q_{\text {total }}\right)$ to the total amount of PCs sent to the column $\left(m_{\text {total }}\right)$ as:

$\% R=\frac{q_{\text {total }}}{m_{\text {total }}} \times 100$

The amount of PCs adsorbed at equilibrium or adsorption capacity, $q_{e}$ (mg of adsorbed phenolic compounds/g of SA-AC beads), and the equilibrium PCs concentration, $C_{e}\left(\mathrm{mg} \mathrm{L}^{-1}\right)$, can be determined from the following equations:

$q_{e}=\frac{q_{\text {total }}}{m}$

$C_{e}=\frac{m_{\text {total }}-q_{\text {total }}}{V_{e f}} \times 1000$

where $m$ total amount of PCs sent to the column (g), and $V_{e f}(\mathrm{~mL})$ volume of the effluent.

The dynamic behavior of the column is approached by the following models: Thomas and Yoon-Nelson.

- Thomas model

The Thomas model is one of the most extensively used breakthrough models in fixed-bed column performance theory. It assumes Langmuir kinetics for adsorption and desorption with no axial dispersion. The model expression can be presented as (Thomas, 1994):

$\frac{C}{C_{0}}=\frac{1}{1+\exp \left(K_{T H} \times q_{0} \times \frac{m}{Q}-K_{T H} \times C_{0} \times t\right)}$

Where $k_{T H}\left(\mathrm{~mL} \mathrm{~min}^{-1} \mathrm{mg}^{-1}\right)$ is the Thomas rate constant, $q_{0}\left(\mathrm{mg} \mathrm{g}^{-1}\right)$ is the adsorption capacity, $m$ total amount of PCs sent to the column $(\mathrm{g})$, and $Q$ is the flow rate that circulates through the column $\left(\mathrm{mL} \mathrm{min}^{-1}\right)$.

- Yoon-Nelson model

The Yoon-Nelson model involves no detailed data about the physical properties of the adsorbent in the fixed-bed column (Yoon and Nelson, 1984). It is expressed as:

$\frac{C}{C_{0}}=\frac{\exp \left(K_{Y N} \times t-\tau \times K_{Y N}\right)}{1+\exp \left(K_{Y N} \times t-\tau \times K_{Y N}\right)}$ 
where $\tau$ is the time required for $50 \%$ adsorbate breakthrough (min) and $k_{Y N}$ is a rate constant that is related to the diffusion characteristics of the mass transfer zone $\left(\mathrm{min}^{-1}\right)$.

\section{Results and discussion}

\subsection{Physicochemical properties of the effluent}

Table 1 presents the physicochemical properties of the studied OMWW. The results showed that OMWW has acidic $\mathrm{pH}$ values equal to 4.8 and 4.7 for modern oil mills and traditional oil mills, respectively, due to the presence of organic acids and PCs. The latter constitute a large proportion of OMWW (4 and $10 \mathrm{~g} \mathrm{~L}^{-1}$ for modern oil mills and traditional oil mills, respectively). This high content of PCs leads to toxicity of this effluent. It is further associated with a high concentration of organic matter, indicated by a very high COD value $\left(110 \mathrm{~g}-\mathrm{O}_{2} \mathrm{~L}^{-1}\right.$

for traditional oil mills). Inorganic loads such as sodium $\left(0.13 \mathrm{~g} \mathrm{~L}^{-1}\right)$, potassium $\left(5.9 \mathrm{~g} \mathrm{~L}^{-1}\right)$, calcium $\left(0.24 \mathrm{~g} \mathrm{~L}^{-1}\right)$ and chloride $\left(3.5 \mathrm{~g} \mathrm{~L}^{-1}\right)$ are high for modern oil mills. These high organic and inorganic loads can make biological treatment extremely difficult and justify the need to implement alternative physicochemical processes such as adsorption. In addition, the concentration of total solids is relatively high $\left(128 \mathrm{~g} \mathrm{~L}^{-1}\right)$.

The analysis of the phenolic composition of this effluent by HPLC (Fig. A1 in Supplementary material) revealed the presence of a varied phenolic pool composed mainly of gallic acid, tyrosol, ferulic acid, caffeic acid, cinnamic acid, and coumaric acid. Magdich et al. (2012) found protocatechuic acid, tyrosol, benzoic acid, ferulic acid and p-coumaric acid. In addition, Tafesh et al. (2014) showed the presence of hydroxytyrosol, acetic acid, 3,4-dihydroxyphenyl, tyrosol, protocatechuic acid, vanillic acid, verbascoside, caffeic acid, p-coumaric acid and ferulic acid. However, Leouifoudi et al. (2014) identified tyrosol and hydroxytyrosol as the main PCs in OMWW, which is similar to the results reported by Achak et al. (2009). PCs do not have the same organic functions; therefore, the adsorption mechanism should not be selective for the organic structure of only one type of PC. 


\subsection{Characterization of the adsorbent}

FTIR spectra of AC and SA-AC beads before and after adsorption are displayed in Fig. A2 (a, b \& c) (Supplementary material). FTIR spectra were obtained in the wavelength range of 4000 $-400 \mathrm{~cm}^{-1}$. The peaks of the FTIR spectrum of AC (Fig. A2 a) at $3457 \mathrm{~cm}^{-1}$ could be the $-\mathrm{OH}$ stretching vibration mode of hydroxyl functional groups. The band at approximately $3032 \mathrm{~cm}^{-1}$ corresponds to the stretching mode of aromatic unsaturated hydrocarbon groups (Iwanow et al., 2020). The symmetrical stretching vibrations of $-\mathrm{CH}_{2}$ - and $-\mathrm{C}=\mathrm{O}$ groups are represented by the bands at1435 $\mathrm{cm}^{-1}$ and $1683 \mathrm{~cm}^{-1}$, respectively (Wang et al., 2019). In the FTIR spectrum of the SA-AC beads (Fig. A2 b), the band at approximately $3308 \mathrm{~cm}^{-1}$ corresponds to the hydroxyl group (-OH group). The stretching vibration of the carbonyl $(-\mathrm{C}=\mathrm{O})$ group appears at $1590 \mathrm{~cm}^{-}$ 1; the symmetrical stretching vibration of $-\mathrm{CH}_{2}$ - is located at $1402 \mathrm{~cm}^{-1}$ (Allwar et al., 2020). The absorption band at $1037 \mathrm{~cm}^{-1}$ is attributed to the bending vibration of the $\mathrm{O}-\mathrm{H}$ group (Nasrullah et al., 2018). There were no significant differences in FTIR spectra between SA-AC beads after adsorption of phenolic compounds and SA-AC beads before adsorption. This result is in accordance with the work previously reported by Shim et al. (2018). These researchers speculated that weak electrostatic interactions and ionic adsorption are prevalent among the studied contaminants and beads.

The textural characteristics of $\mathrm{AC}$ and SA-AC beads were evaluated by SEM, and images at the same magnifications are shown in Fig. $1(\mathrm{a} \& \mathrm{~b})$. In the SEM photograph, the AC surface has a porous morphology caused by the effect of sodium hydroxide as an activating agent at higher temperatures, and the surface of SA-AC beads has a porosity less than that of a pure AC sample. However, SA-AC beads still have a rough and porous surface. Similar texture characteristics were observed by Iqbal et al. (2019), Nasrullah et al. (2018) and Hassan et al. (2014). Nasrullah et al. (2018) and Hassan et al. (2014) used alginate/AC composite beads and AC based on apricot stones, respectively. The SEM of these composite beads shows that the 
surface of the bead composite has a porosity less than that of pure AC, which is similar to the results of the present study.

Fig. A3 (a \& b) (in Supplementary material) shows the EDS spectra of AC and SA-AC beads. EDS analysis revealed the presence of $\mathrm{C}, \mathrm{O}$ and $\mathrm{Na}$ on the $\mathrm{AC}$ surface. After crosslinking (Fig. $\mathrm{A} 3 \mathrm{~b}), \mathrm{Fe}, \mathrm{Al}$ and $\mathrm{Cl}$ appear on the surface. These results confirm the existence of a crosslinking agent on the bead surface. Iqbal et al. (2019) used nano-zero valent copper and activated carbon on hydroxyapatite-alginate beads and $\mathrm{CaCl}_{2}$ as a crosslinking agent, and $\mathrm{EDS}$ analysis showed $\mathrm{Ca}$ and $\mathrm{Cl}$ elements in the prepared beads. In addition, Huixue et al. (2016) used $\mathrm{CaCl}_{2}$ and $\mathrm{FeCl}_{3}$ solutions for the synthesis of $\mathrm{SA}$-carboxymethyl cellulose beads and showed that $\mathrm{Fe}, \mathrm{Ca}$, and $\mathrm{Cl}$ exist on the bead surface and are important for the formation of beads.

The textural characteristics of the raw AC and SA-AC beads are shown in Table S2 (in the Supplementary material). The specific surface areas $\left(S_{B E T}\right)$ of AC and SA-AC were 758 and $523 \mathrm{~m}^{2} \mathrm{~g}^{-1}$, respectively. In addition, the total pore volume $\left(V_{T}\right)$ values were $0.805 \mathrm{~cm}^{3} \mathrm{~g}^{-1}$ for AC and $0.308 \mathrm{~cm}^{3} \mathrm{~g}^{-1}$ for SA-AC beads, which are almost analogous to those reported by other researchers. Kwak et al. (2018) reported $V_{T}$ values of $0.710 \mathrm{~cm}^{3} \mathrm{~g}^{-1}$ for AC and $0.358 \mathrm{~cm}^{3} \mathrm{~g}^{-1}$ for composite beads.

The average $\mathrm{r}^{-}$values were $2.124 \mathrm{~nm}$ and $1.179 \mathrm{~nm}$ for the AC and SA-AC beads, respectively. The decrease in the $\mathrm{r}^{-}$of $\mathrm{AC}$ when mixed with sodium alginate polymer to generate SA-AC beads indicates pore encapsulation by sodium alginate.

These results show the achievement of the feasibility of agglomerating the adsorbent (powder) into macroparticles (beads) by keeping these higher adsorption capacity potentials in order to avoid clogging during the column treatment process. Clogging overcame increase the process life cycle, which decrease the treatment fees. This new design promotes the industrial-scale application to treat effluents in a continuous flow which is the best practical way in the real application (Aziz et al, 2020). 


\subsection{Adsorption efficiency}

Fig. 2a presents the effect of contact time on the removal PCs capacity onto SA-AC beads. The results show that the removal potential increased rapidly at the initial stage until 120 min. Afterwards, the PCs adsorption potential did not change meaningfully until equilibrium was reached.

The initial rapid uptake is caused by the existence of a greater number of active sites on the SAAC beads in the starting stage, and after a lapse of time, the accumulation of PCs in the active sites could be the cause of the decrease in the adsorption of more compounds (Braghiroli et al., 2018).

\subsubsection{Adsorption equilibrium study}

The adsorption isotherms were analyzed to describe the PCs distribution between the liquid and solid phases when the adsorption process attained equilibrium (Liu et al., 2019). Fig. 2b shows the PCs adsorption isotherms onto SA-AC beads. The amount of adsorbed PCs increased with the PCs concentration in solution until it reached $95 \mathrm{mg} \mathrm{g}^{-1}$ at $1000 \mathrm{mg} \mathrm{L}^{-1}$. The increasing amount of PCs in solution causes a rise in the mass transfer driving force (Li et al., 2019).

The fitting results of the adsorption isotherms are shown in Fig. 2 (c \& d) and the parameters are provided in Table S3 (in the Supplementary material). The Langmuir isotherm provided the highest correlation $\left(R^{2}=0.9975\right)$ for PCs adsorption, indicating that adsorption sites are assumed to be energetically homogeneous, and significant PCs monolayer coverage on the outer bead surface is formed without any interaction between the PCs (adsorbed molecules) (Mojoudi et al., 2019). Therefore, the monolayer saturation capacity is $114 \mathrm{mg} \mathrm{g}^{-1}$ beyond which no further adsorption can take place, but full-scale, supplementary experiments (adsorption kinetics) are needed to accurately predict the adsorption capacity of phenolic compounds.

\subsubsection{Modeling of adsorption kinetics}


The rate constants and $R^{2}$ values were calculated from the linearized plots shown in Fig. 3 and are also summarized in Table S4 (in the Supplementary material). Considering the reported $R^{2}$ values, PCs adsorption onto SA-AC beads followed pseudo-second order kinetics, and the correlation coefficients were higher (0.9973) than those of pseudo-first order kinetics (0.7009). The amount of PCs adsorption for pseudo-first order kinetics was $28 \mathrm{mg} \mathrm{g}^{-1}$, whereas that of pseudo-second order kinetics was $68 \mathrm{mg} \mathrm{g}^{-1}$. The calculated $q_{e(c a l c)}$ values using the pseudo-

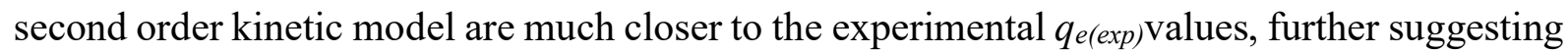
that the adsorption of PCs onto SA-AC beads best fits pseudo-second order kinetics. This model supposes that PCs adsorption is principally controlled by chemisorption, which includes valency changes through sharing or exchange of electrons between the SA-AC beads and the PCs, and external adsorption occurs more often than micropore adsorption (Abdelhay et al., 2017; Tao et al., 2017). Analogous results have also been reported for biochars prepared from olive oil processing waste, $\mathrm{CuO}$-coated olive cake nanocomposites, granular and powdered $\mathrm{AC}$ encapsulated in calcium alginate (beads), and shrimp shell chitin (Elayadi et al., 2020; El Hanandeh et al., 2020; Yuney et al., 2020; Annab et al., 2019). The SA-AC beads used in the present study for PCs removal from a batch test, which were able to remove $68 \mathrm{mg} \mathrm{g}^{-1}$ phenolic compounds, yielded more promising results than other reported adsorbents. In comparison to biochar prepared from olive oil processing waste $\left(51.3 \mathrm{mg} \mathrm{g}^{-1}\right)$, granular and powdered AC encapsulated in calcium alginate beads (14.32 and $35.8 \mathrm{mg} \mathrm{g}^{-1}$, respectively), SA-AC composite beads showed a higher removal capacity. However, in the case of using shrimp shell chitin $\left(1.045 \mathrm{~g} \mathrm{~g}^{-1}\right)$, the adsorption potential was higher than that of the adsorbent used in our study because the initial phenol concentration tested was also higher (10-12 $\left.\mathrm{g} \mathrm{L}^{-1}\right)$. In addition, information on the kinetics of PCs adsorption is necessary to determine the optimum conditions for full-scale PC removal procedures.

\subsubsection{Effect of pH}


The PCs adsorption ability of the SA-AC beads at different $\mathrm{pH}$ values is shown in Fig. 4a. The adsorption capacity of PCs declined from 65 to $12 \mathrm{mg} \mathrm{g}^{-1}$ as the $\mathrm{pH}$ increased from 2 to 10 . This is due to the solubility of PCs that increases when the $\mathrm{pH}$ values decrease. Thus, there was an inverse relationship between the adsorption and solubility of phenolic compounds. However, $\mathrm{pH}$ values influenced the augmentation of oxygen-containing functional groups of SA-AC beads, inducing the effects of $\mathrm{pH}$ on the zeta potentials of SA-AC beads (Tahermansouri et al., 2015; Sun et al., 2019; Al Bsoul et al., 2020). These authors studied the effect of $\mathrm{pH}$ on phenol adsorption using carboxylated multi-walled carbon nanotubes, activated carbons, and ziziphus leaves, respectively. The same results were also reported for the effect of $\mathrm{pH}$.

The main PCs identified in the effluent are mentioned in section 3.1. The pKa of PCs vary from around 3-4 to 10-11, while for most of them it is around 10. Thus, the protonated forms of PCs are predominant from acidic to neutral $\mathrm{pH}$. This form is more prone to be adsorbed on SA-AC beads than the unprotonated form. That is why the adsorption capacity increase when the $\mathrm{pH}$ decrease. The adsorption capacity is higher at an acidic $\mathrm{pH}$ than at a basic $\mathrm{pH}$, which is advantageous in our case since the $\mathrm{pH}$ of real effluent is acidic and thus $\mathrm{pH}$ adjustment would not be required during the treatment. Therefore, in full-scale systems, OMWW can be used directly, which will minimize costs during treatment. Alwan (2008) showed pH-control problems of industrial wastewater treatment plants, which induct technical issues affecting the treatment efficiency, that increase the cost of each treated volume.

\subsubsection{Effect of temperature}

The thermodynamic parameters, i.e., $\Delta G^{\circ}, \Delta S^{\circ}$ and $\Delta H^{\circ}$ values, were obtained from the plot of $\ln \left(\mathrm{K}_{\mathrm{D}}\right)$ versus $1 / \mathrm{T}$ (Fig. $4 \mathrm{~b}$ and Table S5 in the Supplementary material). The positive values of $\Delta H^{\circ}$ suggest an endothermic reaction. In addition, the value of $\Delta H^{\circ}$ was $29 \mathrm{~kJ} \mathrm{~mol}^{-1}$ (higher than $20 \mathrm{~kJ} \mathrm{~mol}^{-1}$ ), suggesting that PCs adsorption onto SA-AC beads involves some chemisorption. The $\Delta G^{\circ}$ values for different temperatures were found to be negative and 
decreased as the temperature decreased; the negative values of $\Delta G^{\circ}\left(19^{\circ} \mathrm{C}:-255 ; 25^{\circ} \mathrm{C}:-1183\right.$; $30^{\circ} \mathrm{C}:-1460 ; 35^{\circ} \mathrm{C}:-1946 \mathrm{~J} \mathrm{~mol}^{-1}$ ) indicate a spontaneous reaction. The positive value of $\Delta S^{\circ}$ $\left(74 \mathrm{~J} \mathrm{~mol}^{-1} \mathrm{~K}^{-1}\right.$ ) corresponds to a dissociative mechanism. Moreover, the positive value of $\Delta S^{\circ}$ also indicates an increased degree of freedom of the PCs in the solution and randomness at the solid/solution interface with some structural variations in the PCs and SA-AC beads during the PCs adsorption process, while the adsorbed molecules of water can be displaced by the PCs molecules (Srivastava et al., 2006; Cheng et al., 2016).

\subsubsection{Fixed-bed column modeling}

During the first 40 min, all the PCs were adsorbed, resulting in a PCs concentration of zero in the outlet water (treated water). As adsorption proceeded, the PCs concentration in the treated water gradually increased. In the up-flow mode, as PCs water is inserted at the bottom of a clean bed of the SA-AC bead medium, most of the PCs are first eliminated in a closed layer at the bottom. As the adsorption proceeded, the lower compartment of the SA-AC beads became saturated with PCs, and the adsorption area advanced vertically through the column (Kundu et al., 2016). Finally, the adsorption area reached the top of the column, and the PCs concentration in the treated water began to increase. A breakthrough curve was generated by plotting the PCs concentration (in $\mathrm{mg} \mathrm{L}^{-1}$ ) in the treated water against time (in min). Fig. 5 shows the breakthrough curve of the adsorption of the phenolic compound onto SA-AC beads. The instant breakthrough time observed was $40 \mathrm{~min}$, and the exhaustion time was $25 \mathrm{~min}$. Different column parameters were determined.

The values of the important design parameters of the breakthrough curves of the bed column for PCs adsorption onto the SA-AC beads were calculated and are shown in Table S6 (in the Supplementary material). As shown in this table, for $C i=4,700 \mathrm{mg} \mathrm{L}^{-1}$ and $Q=2 \mathrm{~mL} \mathrm{~min}{ }^{-1}$, the value of $q_{e}$ reached $159 \mathrm{mg} \mathrm{g}^{-1}$, while the $R$ was $41.6 \%$. 
The SA-AC beads used in the present study for PCs removal from a fixed-bed column yielded more promising results than other reported adsorbents (Kumar and Jena, 2016; Víctor-Ortega et al., 2016; Annab et al., 2019). The adsorbent SA-AC beads were able to remove $159 \mathrm{mg} \mathrm{g}^{-1}$ PCs. In comparison to Amberlyst A26 exchange resin (148 $\left.\mathrm{mg} \mathrm{g}^{-1}\right)$, activated carbon (76 mg g$\left.{ }^{1}\right)$ and bead-activated carbons, calcium alginate $\left(16 \mathrm{mg} \mathrm{g}^{-1}\right)$, SA-AC beads showed higher removal capacity. Furthermore, the adsorbent (SA-AC beads) used in the present study was easily prepared at a low cost.

Data from HPLC analysis of PCs adsorption onto the SA-AC beads before and after treatment in a fixed-bed column are depicted in Fig. A4 (in the Supplementary material). HPLC analysis of the PCs of OMWW after adsorption on the SA-AC beads at 10 min of treatment (Fig. A4a) showed the removal of $100 \%$ tyrosol $\left(361.08 \mathrm{mg} \mathrm{L}^{-1}\right)$, caffeic acid $\left(99.24 \mathrm{mg} \mathrm{L}^{-1}\right)$, ferulic acid (8.44 $\left.\mathrm{mg} \mathrm{L}^{-1}\right)$, coumaric acid $\left(9.12 \mathrm{mg} \mathrm{L}^{-1}\right)$, and cinnamic acid $\left(264.90 \mathrm{mg} \mathrm{L}^{-1}\right)$. It can be noted that the adsorption capacity of tyrosol, caffeic acid, coumaric acid, ferulic acid and cinnamic acid is greater than that of gallic acid $\left(40.50 \mathrm{mg} \mathrm{L}^{-1}\right)$. This could be due to the effect of the structure and $\mathrm{pKa}$ (acid dissociation constant at logarithmic scale) of PCs of the OMWW.

OMWW contains a considerable quantity of mineral ions and organic matter. The physicochemical parameters of the OMWW before and after treatment in a fixed-bed column are described in Table 2. In addition to removing PCs, the SA-AC beads were able to adsorb several ions and colloidal and soluble organic particles with an average of approximately $50 \%$. These contaminants can compete for the adsorption sites and interfere with the removal efficiency. This finding indicates that the surface of the SA-AC bead is highly attractive to multiple elements of OMWW contaminants, which was confirmed by the greater decrease in electrical conductivity (EC) after treatment. SA-AC was also efficient in raising the $\mathrm{pH}$ from 4.79 to 6.12 , so after treatment, we could use it directly without $\mathrm{pH}$ adjustment. 
The parameters given by modeling the experimental breakthrough curves with the Thomas and Yoon-Nelson models for PCs adsorption into SA-AC are presented in Table 3. The $R^{2}$ values (0.9771) demonstrated that the Yoon-Nelson model were compatible and could be used to describe the PCs in SA-AC continuous mode. Furthermore, it is shown in Table 3 that the 50\% breakthrough time $(\tau)$ for 50\% adsorbate breakthrough from the Yoon-Nelson model complies with the experimental values $(\tau(\exp )=141 \mathrm{~min})$. Moreover, error analysis was based on obtaining the best model among the models used for this study. The mean absolute error (MAE) values equaled 0.0619 and 0.0710 for the Thomas model and Yoon-Nelson model, respectively, as shown in Table 3, while the root-mean-square error (RMSE) values for both models were calculated as 0.0727 and 0.0902 , respectively. The MAE and RMSE for the Thomas model were lower than those for the Yoon-Nelson model. The Thomas model fit the experimental data well, meaning that the results followed the kinetics of Langmuir with the hypothesis applicable in a system with a constant flow and a negligible axial dispersion in the adsorption of the column because the motive force of speed follows the reversible reaction of the second-order (Chue, 2010). These results are consistent with those obtained previously in batch experiments.

These data, in addition to their utility in terms of kinetics and isotherms obtained with real effluents, will allow us to design an OMWW treatment system by simulating a full-scale process. In fact, to accurately design a full-scale SA-AC bead adsorption system, in several cases, pilot-scale tests are still required. These modeling results facilitate implementation and offer promising results on PCs breakthroughs in a short period of time. Consequently, the time and cost of a full-scale design are significantly reduced (Merle et al., 2020).

Desorption studies will serve to recover precious PCs from OMWW to regenerate SA-AC beads and to understand the adsorption process. As we showed, PCs adsorption on SA-AC beads is ensured by chemisorption, so desorption experiments were carried out with ethanol according to the procedure described in Section 2.5.2. This was due to the high solubility of 
PCs in ethanol. The results showed that ethanol recovered almost $43 \%$ of the PCs adsorbed. This indicates that ethanol could access SA-AC bead micropores. A similar desorption investigation was also performed and examined for the desorption of phenol using $30 \%(\mathrm{v} / \mathrm{v})$ ethanol solution by neem leaves (Azadirachta indica). Maximum desorption of phenol was achieved (58.5\%) with the batch system (Mandal et al., 2020). Shim et al. (2014) worked with actual Ca-alginate beads containing corn cob silica, immobilized Pseudomonas putida YNSI, and reported successful phenol desorption using $0.05 \mathrm{M} \mathrm{HCl}$. These studies showed that recovery of phenol from beads was substantial (69\%) and that optimization of the desorption step in the continuous process is still needed (Mandal et al., 2014).

Solvent regeneration has numerous advantages for SA-AC bead regeneration since it requires less energy, enables the recovery of PCs and SA-AC beads, and avoids the loss of SA-AC beads. Adsorbent regeneration allows the feasibility of recycling beads for several cycles of OMWW treatment and phenol recovery.

However, adsorbents regeneration is affected by some physical parameters such as the pressure. Shen et al. (2010) highlighted that an increase of feed pressure from 131.32 to $202.65 \mathrm{kPa}$, make increases the adsorbate recovery rate from 48.6 to $78.2 \%$. The pressure drop is impacted by the beads bed thickness (i.e. column height), the bed porosity, as well as the frictional at the surface of the beads (Franchin et al., 2020). This pressure drop across the column increases approximately linearly with breakthrough time (Kratochvil et al., 1998). For this reason and in order to reduce the pressure drop across the bed, it is necessary to periodically backwash the column (Cooney et al., 1998).

To selectively desorb phenolic compounds, electrosorption/desorption experiments will be carried out using a column reactor with a fixed-bed and upward flow. Specific attention will be given to the influence of the acidity constants of PCs on the efficiency of electrosorption to selectively desorb phenolic compounds. 


\section{Conclusions}

New composite beads based on olive pomace with alginate hydrogel were formulated successfully for PC elimination from OMWW. The structure and porous morphology of SAAC beads was confirmed by FTIR, SEM and EDS, which revealed the feasibility of SA-AC beads as potential and low-cost biosorbents. The adsorption of PCs by the SA-AC bead composite fit second-order kinetics and Langmuir isotherms. The results indicated that PC adsorption on SA-AC beads is strongly dependent on $\mathrm{pH}$ and phenol solubility. Thermodynamic analysis indicated that PCs adsorption was spontaneous and endothermic. Thomas and Yoon-Nelson models were selected to fit the experimental data, and the modified Thomas model was better at predicting PCs column adsorption. Finally, the regeneration investigation of SA-AC beads showed that the recovery of phenols from OMWW can be carried out with ethanol.

\section{Acknowledgments}

This work was financed by the PHC TOUBKAL 2019 Project (French-Morocco bilateral program) grant number: $41525 \mathrm{VG}$. The authors would like to thank the National Center for Studies and Research on Water and Energy (Cadi Ayyad University_Morocco) and Laboratoire Réactions et Génie des Procédés (LRGP), CNRS/Université de Lorraine (France) for the technical and scientific support to this work. 


\section{References}

Abdelhay, A., Al Bsoul, A., Al-Othman, A., Al-Ananzeh, N. M., Jum'h, I., Al-Taani, A. A., 2017. Kinetic and thermodynamic study of phosphate removal from water by adsorption onto (Arundodonax) reeds. adsorption science \& technology, 36(1-2), 46-61.

Achak, M., Hafidi, A., Ouazzani, N., Sayadi, S., Mandi, L., 2009. Low cost biosorbent “banana peel" for the removal of PCs from olive mill wastewater: Kinetic and equilibrium studies. Journal of hazardous materials, 166, 117-125.

Al Bsoul, A., Hailat, M., Abdelhay, A., Tawalbeh, M., Al-Othman, A., Al-kharabshehIsra' Nawaf, Al-Taani, A. A., 2020. Efficient removal of phenol compounds from water environment using ziziphus leaves adsorbent. science of the total environment, 143229.

Al-Bsoul, A., Al-Shannag, M., Tawalbeh, M., Al-Taani, A. A., Lafi, W. K., Al-Othman, A., Alsheyab, M., 2020. Optimal conditions for olive mill wastewater treatment using ultrasound and advanced oxidation processes. Science of the total environment, 700, 134576.

Allwar, A., 2020, April. Preparation and characterizations of activated carbon from banana fruit bunch with chemical treatments using hydrothermal processes. In: AIP Conference Proceedings. AIP Publishing LLC, 030028.

Alwan, Ghanim. (2008). PH Control Problems of a Wastewater Treatment Plant. Al-Khwarizmi Engineering Journal, 4, 37-45.

Annab, H., Fiol, N., Villaescusa, I., Essamri, A., 2019. A proposal for the sustainable treatment and valorisation of olive mill wastes. Journal of Environmental Chemical Engineering, 7, 102803.

Arenales-Sierra, I. M., Lobato-Calleros, C., Vernon-Carter, E. J., Hernández-Rodríguez, L., Alvarez-Ramirez, J., 2019. Calcium alginate beads loaded with $\operatorname{Mg}(\mathrm{OH})_{2}$ improve L. casei viability under simulated gastric condition. LWT, 112, 108220. 
Aziz, F., El Achaby, M., Lissaneddine, A., Aziz, K., Ouazzani, N., Mamouni, R., Mandi, L., 2020. Composites with alginate beads: A novel design of nano-adsorbents impregnation for large-scale continuous flow wastewater treatment pilots. Saudi Journal of Biological Sciences, 27, 2499-2508.

Azzam, M. O., Hazaimeh, S. A., 2021. Olive mill wastewater treatment and valorization by extraction/concentration of hydroxytyrosol and other natural phenols. Process Safety and Environmental Protection, 148,495-523.

Badawi, M. A., Negm, N. A., Abou Kana, M. T. H., Hefni, H. H., Abdel Moneem, M. M., 2017. Adsorption of aluminum and lead from wastewater by chitosan-tannic acid modified biopolymers: Isotherms, kinetics, thermodynamics and process mechanism. International Journal of Biological Macromolecules, 99, 465-476.

Baierle, F., John, D. K., Souza, M. P., Bjerk, T. R., Moraes, M. S., Hoeltz, M., Schneider, R. C., 2015. Biomass from microalgae separation by electroflotation with iron and aluminum spiral electrodes. Chemical Engineering Journal, 267, 274-281.

Bampalioutas, K., Vlysidis, A., Lyberatos, G., Vlyssides, A., 2019. Detoxification and methane production kinetics from three-phase olive mill wastewater using Fenton's reagent followed by anaerobic digestion. Journal of Chemical Technology \& Biotechnology, 94, 265-275.

Basu, M., Guha, A. K., Ray, L., 2019. Adsorption of lead on lentil husk in fixed bed column bioreactor. Bioresource technology, 283, 86-95.

Braghiroli, F. L., Bouafif, H., Hamza, N., Neculita, C. M., Koubaa, A., 2018. Production, characterization, and potential of activated biochar as adsorbent for PCs from leachates in a lumber industry site. Environmental Science and Pollution Research, 25, 26562-26575.

Cheng, W. P., Gao, W., Cui, X., Ma, J. H., Li, R. F., 2016. Phenol adsorption equilibrium and kinetics on zeolite X/activated carbon composite. Journal of the Taiwan Institute of Chemical Engineers, 62, 192-198. 
Chu, K. H., 2010. Fixed bed sorption: setting the record straight on the Bohart-Adams and Thomas models. Journal of Hazardous Materials, 177, 1006-1012.

Cooney, E., Stevens, G., Booker, N., Shallcross, D., 1999. Ammonia removal from wastewaters using natural australian zeolite. II. Pilot-scale study using continuous packed column process. Separation Science and Technology, 34(14), 2741-2760.

Duarte, K. R., Justino, C., Panteleitchouk, T., Zrineh, A., Freitas, A. C., Duarte, A. C., RochaSantos, T. A. P., 2014. Removal of PCs in olive mill wastewater by silica-alginate-fungi biocomposites. International Journal of Environmental Science and Technology, 11, 589-596. El Ghadraoui, A., Ouazzani, N., Ahmali, A., El Mansour, T. E. H., Aziz, F., Hejjaj, A., Mandi, L., 2020. Treatment of olive mill and municipal wastewater mixture by pilot scale vertical flow constructed wetland. Desalination and water treatment, 198, 126-139.

El Hanandeh, A., Albalasmeh, A., Gharaibeh, M., Alajlouni, M. 2020. Modification of biochar prepared from olive oil processing waste to enhance phenol removal from synthetic and olive mill wastewater. Separation Science and Technology, 1-13.

El Moudden, H., El Idrissi, Y., El Yadini, A., Harhar, H., Tabyaoui, B., Tabyaoui, M., 2019. Effect of filtration of olive mill wastewater on the phenolic composition and its influence on antioxidant activity.DOI: 10.1080/01496395.2020.1794897

Elayadi, F., Achak, M., Beniich, N., Belaqziz, M., El Adlouni, C., 2020. Factorial Design for Optimizing and Modeling the Removal of Organic Pollutants from Olive Mill Wastewater Using a Novel Low-Cost Bioadsorbent. Water, Air, \&Soil Pollution, 231, 1-16.

Elmansour, T. E., Mandi, L., Ahmali, A., Elghadraoui, A., Aziz, F., Hejjaj, A., Ouazzani, N., 2020. Effect of polyphenols on activated sludge biomass during the treatment of highly diluted olive mill wastewaters: biomass dynamics and purifying performances. Water Science and Technology, 82, 1416-1429. 
Es-sahbany, H., Berradi, M., Nkhili, S., Hsissou, R., Allaoui, M., Loutfi, M., El Youbi, M. S., 2019. Removal of heavy metals (nickel) contained in wastewater-models by the adsorption technique on natural clay. Materials Today: Proceedings, 13, 866-875.

Franchin, G., Pesonen, J., Luukkonen, T., Bai, C., Scanferla, P., Botti, R., Colombo, P., 2020. Removal of Ammonium from Wastewater with Geopolymer Sorbents Fabricated via Additive Manufacturing. Materials \& Design, 109006.

Hassan, A. F., Abdel-Mohsen, A. M., Elhadidy, H., 2014. Adsorption of arsenic by activated carbon, calcium alginate and their composite beads. International journal of biological macromolecules, 68, 125-130.

Ho, Y. S., McKay, G., 1999. Pseudo-second order model for sorption processes. Process biochemistry, 34, 451-465.

Iqbal, J., Shah, N. S., Sayed, M., Imran, M., Muhammad, N., Howari, F. M., Polychronopoulou, K., 2019. Synergistic effects of activated carbon and nano-zerovalent copper on the performance of hydroxyapatite-alginate beads for the removal of $\mathrm{As}^{3+}$ from aqueous solution. Journal of Cleaner Production, 235, 875-886.

Iwanow, M., Gärtner, T., Sieber, V., König, B., 2020. Activated carbon as catalyst support: precursors, preparation, modification and characterization. Beilstein Journal of Organic Chemistry, 16, 1188-1202.

Ji, M., Jiang, X., Wang, F., 2015. A mechanistic approach and response surface optimization of the removal of oil and grease from restaurant wastewater by electrocoagulation and electroflotation. Desalination and Water Treatment, 55, 2044-2052.

Jodra, Y., Mijangos, F., 2003. Phenol adsorption in immobilized activated carbon with alginate gels. Separation science and technology, 38, 1851-1867.

Kaleh, Z., Geißen, S. U., 2016. Selective isolation of valuable biophenols from olive mill wastewater. Journal of environmental chemical engineering, 4, 373-384. 
Kilic, M. Y., Abdelraheem, W. H., He, X., Kestioglu, K., Dionysiou, D. D., 2019. Photochemical treatment of tyrosol, a model phenolic compound present in olive mill wastewater, by hydroxyl and sulfate radical-based advanced oxidation processes (AOPs. Journal of hazardous materials, 367, 734-742.

Kim, T. Y., Jin, H. J., Park, S. S., Kim, S. J., Cho, S. Y., 2008. Adsorption equilibrium of copper ion and phenol by powdered activated carbon, alginate bead and alginate-activated carbon bead. Journal of Industrial and Engineering Chemistry, 14, 714-719.

Kratochvil, D., Volesky, B., 1998. Biosorption of $\mathrm{Cu}$ from ferruginous wastewater by algal biomass. Water Research, 32(9), 2760-2768.

Kumar, A., Jena, H. M., 2016. Removal of methylene blue and phenol onto prepared activated carbon from Fox nutshell by chemical activation in batch and fixed-bed column. Journal of cleaner production, 137, 1246-1259.

Kundu, S. Gupta, A. K. 2005. Analysis and modeling of fixed bed column operations on As (V) removal by adsorption onto iron oxide-coated cement (IOCC. Journal of colloid and interface science, 290, 1, 52-60.

Kwak, H. W., Hong, Y., Lee, M. E., Jin, H. J., 2018. Sericin-derived activated carbon-loaded alginate bead: An effective and recyclable natural polymer-based adsorbent for methylene blue removal. International journal of biological macromolecules, 120, 906-914.

Lagergren, S., 1898. Zurtheorie der sogenannten adsorption gelosterstoffe.

Lawal, A. A., Hassan, M. A., Farid, M. A. A., Yasim-Anuar, T. A. T., Yusoff, M. Z. M., Zakaria, M. R., Shirai, Y., 2020. One-step steam pyrolysis for the production of mesoporous biochar from oil palm frond to effectively remove phenol in facultatively treated palm oil mill effluent. Environmental Technology \& Innovation, 18,100730. 
Leouifoudi, I., Zyad, A., Amechrouq, A., Oukerrou, M. A., Mouse, H. A., Mbarki, M., 2014. Identification and characterisation of PCs extracted from Moroccan olive mill wastewater. Food Science and Technology, 34, 249-257.

Li, W., Yan, J., Yan, Z., Song, Y., Jiao, W., Qi, G., Liu, Y., 2018. Adsorption of phenol by activated carbon in rotating packed bed: Experiment and modeling. Applied Thermal Engineering, 142, 760-766.

Li, Y., Fu, F., Cai, W., Tang, B., 2019. Synergistic effect of mesoporous feroxyhyte nanoparticles and Fe (II) on phosphate immobilization: Adsorption and chemical precipitation. Powder Technology, 345, 786-795.

Liu, S., Cheng, G., Xiong, Y., Ding, Y., Luo, X., 2020. Adsorption of low concentrations of bromide ions from water by cellulose-based beads modified with TEMPO-mediated oxidation and Fe (III) complexation. Journal of hazardous materials, 384, 121195.

Magdich, S., Jarboui, R., Rouina, B. B., Boukhris, M., Ammar, E., 2012. A yearly spraying of olive mill wastewater on agricultural soil over six successive years: impact of different application rates on olive production, phenolic compounds, phytotoxicity and microbial counts. Science of the Total Environment, 430, 209-216.

Mandal, A., Bar, N., Das, S. K., 2020. Phenol removal from wastewater using low-cost natural bioadsorbent neem (Azadirachtaindica) leaves: Adsorption study and MLR modeling. Sustainable chemistry and pharmacy, 17, 100308.

Merle, T., Knappe, D. R., Pronk, W., Vogler, B., Hollender, J., von Gunten, U., 2020. Assessment of the breakthrough of micropollutants in full-scale granular activated carbon adsorbers by rapid small-scale column tests and a novel pilot-scale sampling approach. Environmental Science: Water Research \& Technology, 6(, 2742-2751. 
Mojoudi, N., Soleimani, M., Mirghaffari, N., Belver, C., Bedia, J., 2019. Removal of phenol and phosphate from aqueous solutions using activated carbons prepared from oily sludge through physical and chemical activation. Water Science and Technology, 80, 575-586.

Nadavala, S. K., Swayampakula, K., Boddu, V. M., Abburi, K., 2009. Biosorption of phenol and o-chlorophenol from aqueous solutions on to chitosan-calcium alginate blended beads. Journal of Hazardous Materials, 162, 482-489.

Nasrullah, A., Bhat, A. H., Naeem, A., Isa, M. H., Danish, M., 2018. High surface area mesoporous activated carbon-alginate beads for efficient removal of methylene blue. International journal of biological macromolecules, 107, 1792-1799.

Olusegun, S. J., de Sousa Lima, L. F., Mohallem, N. D. S., 2018. Enhancement of adsorption capacity of clay through spray drying and surface modification process for wastewater treatment. Chemical Engineering Journal, 334, 1719-1728.

Pinto, R. T. P., Lintomen, L., Luz Jr, L. F. L., Wolf-Maciel, M. R., 2005. Strategies for recovering phenol from wastewater: thermodynamic evaluation and environmental concerns. Fluid phase equilibria, 228, 447-457.

Quesada, H. B., de Araújo, T. P., Vareschini, D. T., de Barros, M. A. S. D., Gomes, R. G., Bergamasco, R., 2020. Chitosan, alginate and other macromolecules as activated carbon immobilizing agents: A review on composite adsorbents for the removal of water contaminants. International Journal of Biological Macromolecules.164,2535-2549

Rahmanian, N., Jafari, S. M., Galanakis, C. M., 2014. Recovery and removal of PCs from olive mill wastewater. Journal of the American Oil Chemists' Society, 91, 1-18.

Ren, H., Gao, Z., Wu, D., Jiang, J., Sun, Y., Luo, C., 2016. Efficient Pb (II) removal using sodium alginate-carboxymethyl cellulose gel beads: Preparation, characterization, and adsorption mechanism. Carbohydrate polymers, 137, 402-409. 
Shen, C., Yu, J., Li, P., Grande, C. A., Rodrigues, A. E., 2010. Capture of $\mathrm{CO}_{2}$ from flue gas by vacuum pressure swing adsorption using activated carbon beads. Adsorption, 17(1), 179-188. Shim, J., Kumar, M., Goswami, R., Mazumder, P., Oh, B. T., Shea, P. J., 2019. Removal of pcresol and tylosin from water using a novel composite of alginate, recycled $\mathrm{MnO}_{2}$ and activated carbon. Journal of hazardous materials, 364, 419-428.

Shim, J., Lim, J.-M., Shea, P. J., Oh, B.-T., 2014. Simultaneous removal of phenol, Cu and Cd from water with corn cob silica-alginate beads. Journal of hazardous materials, 272, 129-136. Soto, M. L., Moure, A., Domínguez, H., Parajó, J. C., 2011. Recovery, concentration and purification of PCs by adsorption: A review. Journal of Food Engineering, 105, 1-27.

Srivastava, V. C., Swamy, M. M., Mall, I. D., Prasad, B., Mishra, I. M., 2006. Adsorptive removal of phenol by bagasse fly ash and activated carbon: equilibrium, kinetics and thermodynamics. Colloids and surfaces a: physicochemical and engineering aspects, 272, 89104.

Sun, J., Liu, X., Zhang, F., Zhou, J., Wu, J., Alsaedi, A., Li, J., 2019. Insight into the mechanism of adsorption of phenol and resorcinol on activated carbons with different oxidation degrees. Colloids and Surfaces A: Physicochemical and Engineering Aspects, 563, 22-30.

Tafesh, A., Najami, N., Jadoun, J., Halahlih, F., Riepl, H., Azaizeh, H., 2011. Synergistic antibacterial effects of polyPCs from olive mill wastewater. Evidence-Based Complementary and Alternative Medicine,1-9.

Tahermansouri, H., Dehghan, Z., Kiani, F., 2015. Phenol adsorption from aqueous solutions by functionalized multiwalled carbon nanotubes with a pyrazoline derivative in the presence of ultrasound. RSC Advances, 5, 44263-44273.

Tao, J., Huo, P., Fu, Z., Zhang, J., Yang, Z., Zhang, D., 2019. Characterization and phenol adsorption performance of activated carbon prepared from tea residue by $\mathrm{NaOH}$ activation. Environmental technology, 40, 171-181. 
Víctor-Ortega, M. D., Ochando-Pulido, J. M., \&Martínez-Ferez, A., 2016. Performance and modeling of continuous ion exchange processes for phenols recovery from olive mill wastewater. Process safety and environmental protection, 100, 242-251.

Wang, W., Xu, S., Wang, K., Liang, J., Zhang, W., 2019. De-intercalation of the intercalated potassium in the preparation of activated carbons by $\mathrm{KOH}$ activation. Fuel Processing Technology, 189, 74-79.

Yuney, K., Oladipo, A. A., Gazi, M., Younis, D. Z., 2020. CuO coated olive cake nanocomposites for rapid phenol removal and effective discoloration of high strength olive mill wastewater. Chemosphere, 253,126703.

Zagklis, D. P., Vavouraki, A. I., Kornaros, M. E., Paraskeva, C. A., 2015. Purification of olive mill wastewater phenols through membrane filtration and resin adsorption/desorption. Journal of hazardous materials, 285, 69-76. 